This item was submitted to Loughborough's Research Repository by the author.

Items in Figshare are protected by copyright, with all rights reserved, unless otherwise indicated.

\title{
Modelling of deposition processes on the TiO2 rutile (110) surface
}

PLEASE CITE THE PUBLISHED VERSION

http://dx.doi.org/10.1016/j.nimb.2009.06.093

PUBLISHER

(c) Elsevier

VERSION

AM (Accepted Manuscript)

LICENCE

CC BY-NC-ND 4.0

REPOSITORY RECORD

Vernon, Louis J., Roger Smith, and Steven D. Kenny. 2019. "Modelling of Deposition Processes on the Tio2 Rutile (110) Surface”. figshare. https://hdl.handle.net/2134/11626. 
This item was submitted to Loughborough's Institutional Repository (https://dspace.lboro.ac.uk/) by the author and is made available under the following Creative Commons Licence conditions.

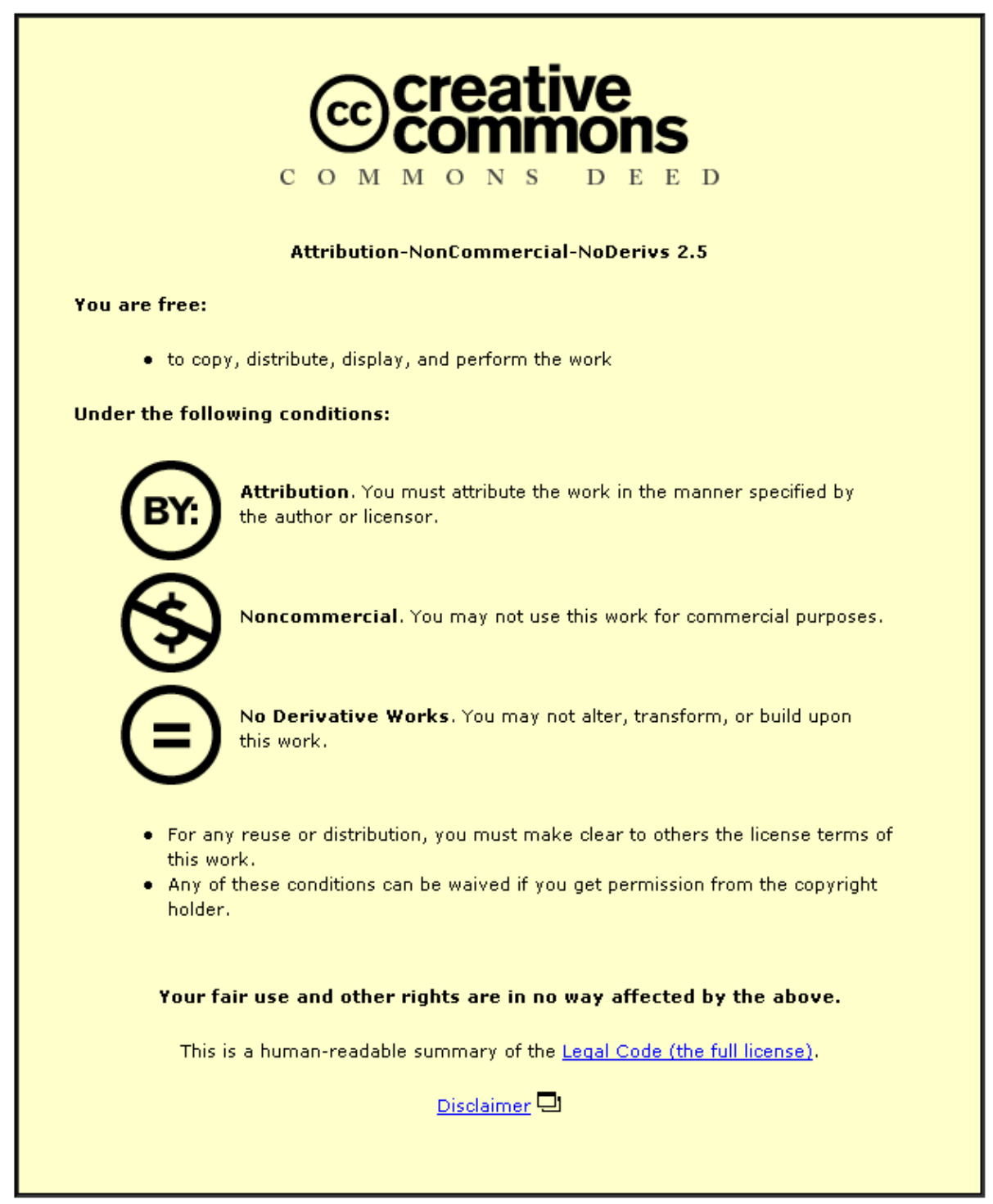

For the full text of this licence, please go to: http://creativecommons.org/licenses/by-nc-nd/2.5/ 


\title{
Modelling of Deposition Processes on the $\mathrm{TiO}_{2}$ Rutile (110) Surface
}

\author{
L.J. Vernon, Roger Smith, S.D. Kenny* \\ Department of Mathematical Sciences, Loughborough University, Loughborough, \\ Leicestershire, LE11 3TU, UK.
}

\begin{abstract}
Deposition of $\mathrm{Ti}_{x} \mathrm{O}_{y}$ clusters onto the rutile $\mathrm{TiO}_{2}$ (110) surface has been modelled using empirical potential based molecular dynamics. Deposition energies in the range 10-40 eV have been considered so as to model typical deposition energies of magnetron sputtering. Defects formed as a function of both the deposition energy and deposition species have been studied.

The results show that in the majority of cases Ti interstitial atoms are formed, irrespective of whether Ti was contained within the deposited cluster. Furthermore that the majority of these interstitials are formed by displacing a surface Ti atom into the intersitial site. O surface atoms are also relatively common, with $\mathrm{Ti}$ and $\mathrm{TiO}_{2}$ surface units often occurring when the deposited cluster contains Ti but becoming less frequent as the deposition energy is increased. Structures that would give rise to the growth of further layers of rutile are not observed and in the majority of the simulations the energy barriers for diffusion of the end-products is high.
\end{abstract}

Key words: Computer simulations, Molecular dynamics, Deposition, Titania, Film growth

PACS: 68.43.Fg 68.43.Mn 68.47.Gh

\section{Introduction}

Titania in the rutile structure is an important material with many uses including acting as a pigment in paint and as a major component of sunscreen [1]. The focus of this work is its use in optical thin films where its high refractive index and its adsorption of UV radiation are both important properties [2].

* Corresponding author, e-mail: S.D.Kenny@lboro.ac.uk. 
These films are typically grown by deposition techniques, with the films we are aiming to model being grown by reactive magnetron sputtering [3].

There are numerous experimental studies of the growth of rutile [4-6] including work on real-time atomic resolution STM of the growth process. These have been able to indicate the likely barrier heights that control the growth of the rutile surface but have not been able to indicate the growth mechanism. It has, however, been shown that if $\mathrm{O}$ atoms are deposited onto a Ti rich rutile surface then surface growth occurs. It has been proposed that this is due to Ti interstitials coming out of the bulk and forming new layers of $\mathrm{TiO}_{2}$ with surface $\mathrm{O}$ atoms.

In this study we have investigated the deposition of units of $\mathrm{Ti}_{x} \mathrm{O}_{y}$ at energies typical of those in reactive magnetron sputtering. These simulations have been employed to study the typical defects formed during the deposition process involved in the growth of $\mathrm{TiO}_{2}$. This has been investigated as a function of both the deposition energy and the deposition species. These simulations provide insight into possible reaction pathways that require further investigation.

\section{Methodology}

The variable charge QEq model [7] of Halil et al. [8] has been used to model the rutile $\mathrm{TiO}_{2}$. The use of a variable charge model is essential for modelling this problem due to the lack of stoichiometry in many of the systems of interest. Charges on the atoms at each step in the MD simulation have been found by performing a constrained conjugate gradient minimisation of the component of internal energy relating to the charges on the atoms. The Halil et al. empirical potential has been modified through the introduction of a repulsive shortranged Ti-Ti interaction, as this was found to be essential for the deposition of Ti containing ad-units. This has been achieved through the use of the purely repulsive ZBL potential [9] at distances shorter than $2.5 \AA$. Integration of Newton's equation of motion has been performed using the velocity Verlet algorithm [10] with a time step of $1 \mathrm{fs.}$

Ti, O, TiO and $\mathrm{TiO}_{2}$ ad-units have been deposited onto a lattice containing 1800 atoms. Periodic boundary conditions were employed, with the Coulomb interaction between the atoms calculated using Ewald summations. The adunits were started a distance of $5 \AA$ above the surface, with the lateral position chosen randomly from an area covering one surface unit cell. Depositions were carried out with an initial kinetic energy of 10, 20, 30 or $40 \mathrm{eV}$ being given to the ad-units. For each particular energy and ad-unit 50 depositions were carried out each on to the pristine (110) surface so as to accumulate sufficient statistics. The bottom two layers of the slab were fixed so as to prevent drift of 
the whole slab. The $\mathrm{TiO}_{2}$ slab was initially at $0 \mathrm{~K}$ and in order to remove the energy due to the deposited ad-unit a Berendsen thermostat [11] was attached to the bottom two layers above the fixed zone.

There are a number of defects that can be formed at or near the rutile (110) surface and these have been used to assess the damage caused by the deposited ad-units. Fig 1 shows a schematic of the unreconstructed rutile (110) surface, there are a number of important features on the surface. The surface has twofold coordinated $\mathrm{O}$ atoms, which make up the $\mathrm{O}$ rows, in line and beneath these are the six-fold coordinated $\mathrm{Ti}$ atoms. Midway between $\mathrm{O}$ rows are the five-fold coordinated $\mathrm{Ti}$ atoms, which are bonded to the surface three-fold coordinated $\mathrm{O}$ atoms.

We have labelled vacancies caused by knocking a Ti atom from the five-fold coordinated site a type- $1 \mathrm{Ti}$ vacancy, whilst those caused by knocking a Ti atom from the six-fold coordinated site are labelled a type-2 Ti vacancy. Due to the presence of the surface two distinct Ti interstitial sites exist in the layer below the surface. We have labelled the Ti interstitial that sits below the threefold coordinated $\mathrm{O}$ atom as a type- $1 \mathrm{Ti}$ interstitial, whilst the one that sits between two three-fold coordinated $\mathrm{O}$ atoms is labelled as a type-2 interstitial. Using the Halil et al. potential gives an energy difference of $0.1 \mathrm{eV}$ between the two interstitials with the type- 1 site being favoured. Three $\mathrm{O}$ vacancy sites are regularly observed in the simulations. An $\mathrm{O}$ vacancy in the ad-row is labelled as a type- 1 vacancy, an $\mathrm{O}$ vacancy from the three-fold coordinated surface $\mathrm{O}$ atoms as a type- 2 vacancy and finally when a deposited $\mathrm{O}$ atom is observed to be ejected from the surface we label this as a type-3 vacancy. TiO ad-units are seen to bond so that the Ti atom sits in the upper hollow site, bonded to two two-fold coordinated $\mathrm{O}$ atoms and one three-fold coordinated $\mathrm{O}$ atom, with the $\mathrm{O}$ atom above one of the five-fold coordinated $\mathrm{Ti}$ atoms. Finally the $\mathrm{TiO}_{2}$ is seen to bond in two sites, both have the Ti atom sitting in the upper hollow site. In site 1 both $\mathrm{O}$ atoms sit above five-fold coordinated $\mathrm{Ti}$ atoms, whilst in site 2 one $\mathrm{O}$ atom sits above a five-fold coordinated $\mathrm{Ti}$ atom while the other aligns so that the Ti-O bond points almost orthogonally to the surface.

The statistics collected to indicate damage to the surface sample the types of defects created rather than the number. Thus if two type $1 \mathrm{Ti}$ interstitials were formed then this would simply count as the formation of a type 1 interstitial. In order to record the level of damage caused by a deposition event the concept of a damage number has been introduced. This records the average number of defects created for the deposition of a particular ad-unit as a particular energy. Statistics on the defects created are presented as a percentage of the simulations in which those defects are observed. 


\section{Results}

The statistics regarding defects created and the damage imparted to the rutile $\mathrm{TiO}_{2}$ (110) surface during the deposition of Ti atoms at 10, 20, 30 and $40 \mathrm{eV}$ are given in table 1 . There are a number of interesting points to note in the table. Firstly the primary damage is the formation of Ti interstitials and furthermore there appears to be a switch between the formation of type- 1 and type- 2 interstitials that occurs between 10 and $20 \mathrm{eV}$. The number of $\mathrm{Ti}$ vacancies are much lower than the number of interstitials, this is due to the fact that most interstitials are formed by a replacement mechanism. Where by the incident Ti atom displaces a five- or six-fold coordinated Ti atom into an interstitial site and the incident atom then replaces the surface Ti atom.

Table 2 contains the results from depositing a $\mathrm{TiO}$ unit onto the rutile $\mathrm{TiO}_{2}$ (110) surface at energies of $10,20,30$ and $40 \mathrm{eV}$. The main feature of these results are that highly stable $\mathrm{TiO}_{2}$ surface units are formed in a small percentage of cases, via the displacement of a two-fold coordinated $\mathrm{O}$ atom. A large number of $\mathrm{Ti}$ interstitials are seen to form at all energies with an inversion between type- 1 and type- 2 defects occurring between 30 and $40 \mathrm{eV}$. The greater propensity for $\mathrm{TiO}$ to form type- $1 \mathrm{Ti}$ interstitials is due to the direct formation of these interstitials, in these cases the $\mathrm{TiO}$ unit is attracted to the upper hollow site but on impact with the surface the Ti atom moves directly into the interstitial site.

Results from the deposition of $\mathrm{TiO}_{2}$ onto the rutile $\mathrm{TiO}_{2}$ (110) surface are given in table 3 . It can be seen that at $10 \mathrm{eV}$ the vast majority of the $\mathrm{TiO}_{2}$ units deposited finish as absorbed $\mathrm{TiO}_{2}$ units. As the deposition energy is increased the $\mathrm{TiO}_{2}$ units are seen to dissociate, initially forming $\mathrm{Ti}$ interstitials and surface $\mathrm{O}$ atoms and as the energy increases further $\mathrm{TiO}$ surface units become more prevalent. At the 30 and $40 \mathrm{eV}$ deposition energies $\mathrm{O}$ atoms are seen to be sputtered from the surface (O type-3 vacancies).

The results for the deposition of $\mathrm{O}$ onto the (110) rutile $\mathrm{TiO}_{2}$ can be seen in table 4. It can be seen that the primary defect created is an $\mathrm{O}$ atom on the surface. Above $10 \mathrm{eV}$ a number of Ti interstitials are also created which form through the creation of Ti vacancies in the surface layer, the number of these rise as the deposition energy is increased. The only other form of defect observed are $\mathrm{O}$ vacancies in the surface. 


\section{Conclusions}

Simulations of the deposition of small $\mathrm{Ti}_{x} \mathrm{O}_{y}$ clusters onto the (110) rutile $\mathrm{TiO}_{2}$ surface at 10, 20, 30 and $40 \mathrm{eV}$ have been simulated. In order to facilitate this it was necessary to introduce a short ranged $\mathrm{Ti}$-Ti repulsive potential to the potential of Halil et al. [8].

The main defects created were $\mathrm{Ti}$ interstitials, which were formed irrespective of the species deposited. In the majority of cases these were formed by displacing a surface $\mathrm{Ti}$ atom into an interstitial site. O surface atoms were common in many of the simulations, being observed less frequently only when $\mathrm{Ti}$ atoms were deposited. Both $\mathrm{TiO}$ and $\mathrm{TiO}_{2}$ surface units were observed when a unit containing $\mathrm{Ti}$ was deposited, these often became less frequent as the deposition energy was increased and thus the clusters tended to break up.

Mechanisms to allow $\mathrm{TiO}_{2}$ to grow in the rutile phase were not observed from the deposition events. Furthermore the majority of the structures formed had large energy barriers for diffusion. Thus it is not clear from the deposition events alone how further layers of rutile would grow. Further work on the $\mathrm{TiO}_{2}$ potential is necessary to allow the formation of $\mathrm{O}_{2}$ molecules so that these can be deposited onto the surface, as these are known to be present in the deposition experiments.

\section{Acknowledgements}

The calculations presented in this work have been performed on the resources of Loughborough University's high performance computing centre. This work was funded by EPSRC grant no. EP/C524322/1.

\section{References}

[1] M. Wang, The Chemical Educator 3 (1998) 1.

[2] Z. Zhang, AIChE Journal 46 (2000) 1461.

[3] J. Š́cha, Plasma Processes and Polymers 4 (2007) S345.

[4] R. A. Bennet, P. Stone, N. J. Price and M. Bowker, Phys. Rev. Lett. 82 (1999) 3831.

[5] M. L, W. Hebenstreit, L. Gross, U. Diebold, M. A. Henderson, D. R. Jennison, P. A. Schultz and M. P. Sears, Surface Science 437 (1999) 173. 
[6] K. F. McCarty, Surface Science 543 (2003) 185.

[7] A.K. Rappe and W.A. Goddard, J Phys Chem-Us 95 (1991) 3358.

[8] A. Hallil, R. Tétot, F Berthier, I Braems and J Creuze, Phys. Rev. B 73 (2006) 165406 .

[9] J.F. Ziegler, J.P. Biersack and U. Littmark, The Stopping and Range of Ions in Solids Pergamon, New York (1985).

[10] M. P. Allen and D. J. Tildesley, Computer Simulations of Liquids Oxford University Press (1989).

[11] H.J.C. Berendsen, J.P.M. Postma, W.F. an Gunsteren, A. Dinola and B. Haak, J. Chem. Phys. 81 (1984) 3684.

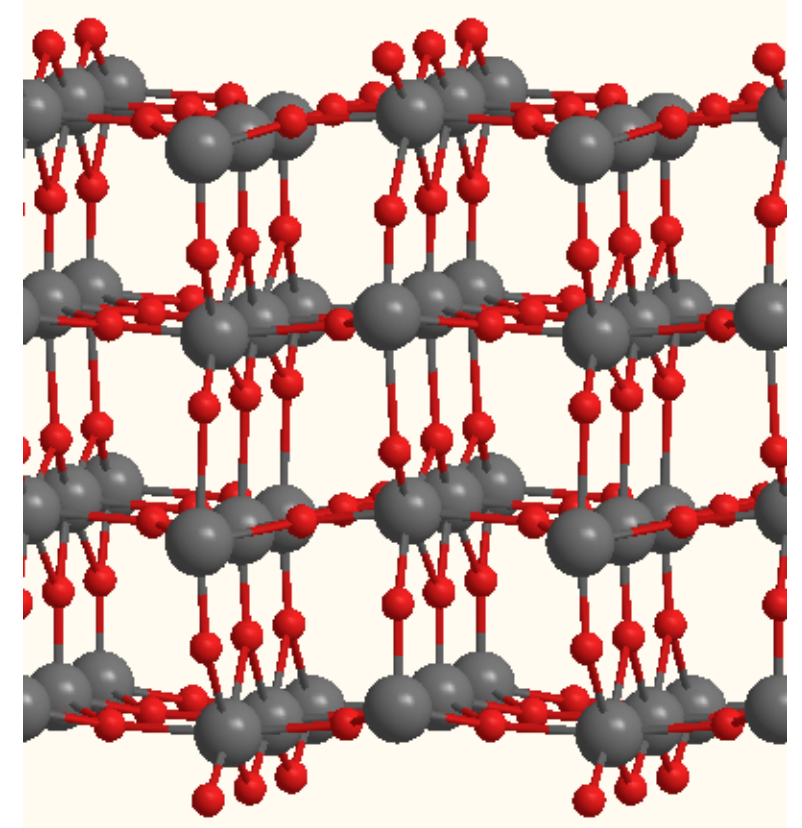

Fig. 1. Structure of the unreconstructed (110) surface of rutile $\mathrm{TiO}_{2}, \mathrm{O}$ atoms are represented by red spheres and Ti atoms by grey spheres. 


\begin{tabular}{|l|c|c|c|c|}
\hline $\mathrm{Ti}$ & $10 \mathrm{eV}$ & $20 \mathrm{eV}$ & $30 \mathrm{eV}$ & $40 \mathrm{eV}$ \\
\hline \multicolumn{5}{|c|}{ Surface } \\
\hline $\mathrm{O}$ & 5 & 9 & 6 & 50 \\
\hline $\mathrm{TiO}$ & 16 & 9 & 11 & 0 \\
\hline \multicolumn{5}{|c|}{ Interstitials } \\
\hline $\mathrm{Ti} \# 1$ & 68 & 40 & 39 & 58 \\
\hline $\mathrm{Ti} \# 2$ & 26 & 73 & 83 & 83 \\
\hline \multicolumn{5}{|c|}{ Vacancies } \\
\hline $\mathrm{Ti} \# 1$ & 21 & 59 & 78 & 50 \\
\hline $\mathrm{Ti} \# 2$ & 5 & 0 & 22 & 8 \\
\hline $\mathrm{O} \# 1$ & 11 & 14 & 17 & 33 \\
\hline $\mathrm{O} \# 2$ & 11 & 5 & 0 & 17 \\
\hline $\mathrm{O} \# 3$ & 0 & 0 & 11 & 8 \\
\hline Damage & 0.68 & 1.5 & 2.2 & 2.5 \\
\hline
\end{tabular}

Table 1

Average number of defects formed and damage imparted to the the rutile $\mathrm{TiO}_{2}$ (110) surface due to the deposition of a Ti atom at 10, 20, 30 and $40 \mathrm{eV}$. 


\begin{tabular}{|l|c|c|c|c|}
\hline $\mathrm{TiO}$ & $10 \mathrm{eV}$ & $20 \mathrm{eV}$ & $30 \mathrm{eV}$ & $40 \mathrm{eV}$ \\
\hline \multicolumn{5}{|c|}{ Surface } \\
\hline $\mathrm{O}$ & 47 & 58 & 85 & 60 \\
\hline $\mathrm{TiO}$ & 38 & 21 & 8 & 27 \\
\hline $\mathrm{TiO}_{2} \# 1$ & 10 & 0 & 0 & 0 \\
\hline $\mathrm{TiO}_{2} \# 2$ & 5 & 5 & 0 & 4 \\
\hline \multicolumn{5}{|c|}{ Interstitials } \\
\hline $\mathrm{Ti} \# 1$ & 33 & 58 & 69 & 60 \\
\hline $\mathrm{Ti} \# 2$ & 29 & 36 & 38 & 73 \\
\hline \multicolumn{5}{|c|}{ Vacancies } \\
\hline $\mathrm{Ti} \# 1$ & 10 & 26 & 15 & 40 \\
\hline $\mathrm{Ti} \# 2$ & 14 & 16 & 23 & 60 \\
\hline $\mathrm{O} \# 1$ & 14 & 58 & 15 & 33 \\
\hline O \#2 & 0 & 0 & 0 & 17 \\
\hline O \#3 & 0 & 21 & 23 & 33 \\
\hline Damage & 0.66 & 1.05 & 1 & 3.2 \\
\hline $\mathrm{Tab} 2$
\end{tabular}

Table 2

Average number of defects formed and damage imparted to the the rutile $\mathrm{TiO}_{2}$ (110) surface due to the deposition of a TiO unit at 10, 20, 30 and $40 \mathrm{eV}$. 


\begin{tabular}{|l|c|c|c|c|}
\hline $\mathrm{TiO}_{2}$ & $10 \mathrm{eV}$ & $20 \mathrm{eV}$ & $30 \mathrm{eV}$ & $40 \mathrm{eV}$ \\
\hline \multicolumn{5}{|c|}{ Surface } \\
\hline $\mathrm{O}$ & 21 & 64 & 76 & 60 \\
\hline $\mathrm{TiO}$ & 3 & 12 & 12 & 22 \\
\hline $\mathrm{TiO}_{2} \# 1$ & 56 & 26 & 16 & 6 \\
\hline $\mathrm{TiO}_{2} \# 2$ & 24 & 3 & 0 & 11 \\
\hline \multicolumn{5}{|c|}{ Interstitials } \\
\hline $\mathrm{O}$ & 0 & 0 & 4 & 6 \\
\hline $\mathrm{Ti} \# 1$ & 3 & 29 & 32 & 33 \\
\hline $\mathrm{Ti} \# 2$ & 27 & 41 & 52 & 61 \\
\hline \multicolumn{5}{|c|}{ Vacancies } \\
\hline $\mathrm{Ti} \# 1$ & 15 & 26 & 16 & 39 \\
\hline $\mathrm{Ti} \# 2$ & 0 & 6 & 4 & 6 \\
\hline O \#1 & 0 & 6 & 0 & 6 \\
\hline O \#3 & 0 & 8 & 24 & 39 \\
\hline $\mathrm{Damage}$ & 0.29 & 0.76 & 0.96 & 1.15 \\
\hline $\mathrm{Ta}$ & & & \\
\hline
\end{tabular}

Table 3

Average number of defects formed and damage imparted to the the rutile $\mathrm{TiO}_{2}$ (110) surface due to the deposition of a $\mathrm{TiO}_{2}$ unit at 10, 20, 30 and $40 \mathrm{eV}$. 


\begin{tabular}{|l|c|c|c|c|}
\hline $\mathrm{O}$ & $10 \mathrm{eV}$ & $20 \mathrm{eV}$ & $30 \mathrm{eV}$ & $40 \mathrm{eV}$ \\
\hline \multicolumn{5}{|c|}{ Surface } \\
\hline $\mathrm{O}$ & 91 & 86 & 89 & 88 \\
\hline \multicolumn{5}{|c|}{ Interstitials } \\
\hline $\mathrm{Ti} \# 1$ & 0 & 5 & 22 & 13 \\
\hline $\mathrm{Ti} \# 2$ & 0 & 23 & 11 & 50 \\
\hline \multicolumn{5}{|c|}{ Vacancies } \\
\hline $\mathrm{Ti} \# 1$ & 0 & 23 & 22 & 63 \\
\hline $\mathrm{Ti} \# 2$ & 0 & 5 & 0 & 0 \\
\hline $\mathrm{O} \# 1$ & 9 & 14 & 22 & 25 \\
\hline O \#2 & 0 & 0 & 0 & 13 \\
\hline O \#3 & 9 & 23 & 33 & 25 \\
\hline Damage & 0.18 & 0.9 & 1.1 & 2.5 \\
\hline
\end{tabular}

Table 4

Average number of defects formed and damage imparted to the the rutile $\mathrm{TiO}_{2}$ (110) surface due to the deposition of a $\mathrm{O}$ atom at 10,20,30 and $40 \mathrm{eV}$. 